\title{
Skin color affect the replacement of amalgam for composite in posterior restorations: a birth-cohort study
}

\author{
Luiz Alexandre CHISINI(a) iD \\ Kauê COLLARES(a) iD \\ João Luiz Dorneles BASTOS(b) \\ Karen Glazer PERES(c) iD \\ Marco de Anselmo PERES(c) iD \\ Bernardo Lessa HORTA(d) ID \\ Flávio Fernando DEMARCO(a) iD \\ Marcos Britto CORREA(a) iD \\ (a) Federal University of Pelotas - UFPel, Graduate \\ Program in Dentistry, Pelotas, RS, Brazil. \\ (b) Federal University of Santa Catarina - \\ UFSC, Post-Graduate Program in Public \\ Health, Florianópolis, SC, Brazil \\ (c)The University of Adelaide, Australian \\ Research Centre for Population Oral Health, \\ School of Dentistry, Adelaide, Australia. \\ (d) Federal University of Pelotas - UFPel, Post \\ Graduate Program in Epidemiology, Pelotas, \\ RS, Brazil.
}

Declaration of Interests: The authors certify that they have no commercial or associative interest that represents a conflict of interest in connection with the manuscript.

Corresponding Author:

Marcos Britto Correa

E-mail: marcosbrittocorrea@hotmail.com

hitps://doi.org/10.1590/1807-3107bor-2019.vol33.0054

Submitted: February 2, 2019

Accepted for publication: May 20, 2019

Last revision: June 6, 2019

\begin{abstract}
The aim of present study was to estimate the occurrence and associated factors for replacement of amalgam posterior restorations. A representative sample of all 5,914 births from the 1982 in Pelotas birth cohort study was prospectively investigated, and the posterior restorations were assessed at $24(n=720)$ and 31 years of age $(n=539)$. Individual-level variables, i.e., demographic characteristics, socio-economic factors, oral health conditions and use of dental services, were collected from different waves of the cohort. Toothlevel variables included dental group, estimated time in mouth of each amalgam restoration, and number of restored dental surfaces. Thus, 246 individuals presented 718 amalgam restorations at 24 years of age. After 7 seven years of follow-up, 18.9\% of these restorations had been replaced with composite resins. Multilevel Poisson regression models showed that, compared to white individuals, blacks presented a lower risk of replacement of amalgam restorations for composite resins (IRR - 0.39 [0.16-0.95]). Individuals with high educational level at age 31 showed an increased likelihood of replacement of amalgam restorations. Therefore, skin color affects the replacement of amalgam for composite resin in posterior restorations.
\end{abstract}

Keywords: Epidemiology; Cohort Studies; Dental Restoration Repair; Composite Resins.

\section{Introduction}

Dental caries is a public health problem, both for deciduous and permanent dentitions, which shows a high prevalence rates and affects more than 2,4 billion adults and 621 million children worldwide. ${ }^{1}$ Direct restorations are still the most frequently technique used to treat the sequelae of dental caries. ${ }^{2,3,4}$ While amalgam was the most frequently used dental material to restore decayed teeth in the $20^{\text {th }}$ century, its use showed a sudden decline in recent decades mainly due to the development of esthetic materials, and the banning of amalgam-based fillings in several countries as a measure to reduce exposure to lead-containing materials. ${ }^{2,5}$ This, despite the fact that amalgam is a low-cost dental material, as well as less sensitive to varying clinical techniques or even operator proficiency. ${ }^{6}$

With the development of dentin acid etching techniques, composite resin has been the material of choice by professionals and patients to restore decayed 
teeth., ${ }^{78}$ Clinical studies have shown that composite resins have acceptable rates of longevity. 9,10,11 The literature has pointed out, though, that patient-related risk factors, such as the presence of high occlusal stress and/or elevated caries risk, have an important influence on restoration longevity. ${ }^{12,13}$ Patient- and dentist-related factors play a key role both in the failure of dental materials as well as the decision on whether to replace them or not. ${ }^{13}$ A population-based study suggested that socioeconomic and demographic factors influenced the choice of restorative materials. ${ }^{8}$ Higher levels of mother's schooling were associated with use of composite resin; on the other hand, patients who use health insurance services and with high caries risk were more likely to have their posterior teeth restored with amalgam. ${ }^{8,14,15,16}$ Due to the increase in demands for high aesthetic standards in contemporary society, ${ }^{17}$ stimulated in part by the dental materials industry, as well as dental professionals, satisfactory amalgam restorations have been replaced for composite resins restorations even without clinical indication..$^{18,19}$ The replacement of restorations only for aesthetic reasons leads to unnecessary loss of healthy tooth structure, ${ }^{20}$ especially when involving posterior teeth, which a priori do not interfere with the patient's smile or social interactions. This demand may result in overtreatment, as well as the so-called repetitive restorative cycle. ${ }^{20}$

Even though replacement of amalgam restorations is believed to be a frequent procedure in current dental practice, ${ }^{2}$ there is a paucity of studies estimating the rate of amalgam replacement, as well as the factors that may lead to it in population-based samples. Given that both individual and tooth-related factors may influence the replacement of these restorations, the present study aimed to estimate the occurrence and associated factors for replacement of amalgam posterior restorations in a population sample of individuals aged 24 to 31 in Southern Brazil. The hypothesis of present study is that both individual as tooth-level variables influencing the occurrence of replacement of amalgam restorations.

\section{Methodology}

This study was reported according the STROBE guidelines for observational studies. ${ }^{21}$ This cohort was conducted in Pelotas, a medium-sized city located in Southern Brazil. In 1982, all live births occurring in the three maternity hospitals of the city were identified and included in a perinatal health survey. As a result, 5,914 children were included in this birth cohort study.

In 1997, a systematic sample of $70(27 \%)$ of the 259 census tracts in the city was selected, and all existing households in these tracts were visited. This allowed us to interview 1,076 adolescents from the original birth cohort. A random sample of 900 out of the 1,076 initially identified respondents was then selected and 88815 -year-old adolescents were included in the first 1982 Pelotas birth cohort Oral Health Study (OHS-97). In 2006, when the OHS-97 participants were 24 years old, $720(720 / 888=81 \%)$ were re-interviewed and dentally examined (OHS-06). This was the first OHS to include assessments of posterior restorations (fillings in molar and pre-molar teeth) in addition to other oral health conditions. In 2013, OHS-97 participants were contacted again for a new OHS, the OHS-13. As in previous studies, the OHS-13 comprised a health interview and a dental examination, including inspection of posterior restorations $(n=539)$. Only individuals presenting amalgam restorations at 24 years of age were included in this study $(\mathrm{n}=246)$.

\section{Outcome}

The outcome of the present study was the replacement of amalgam restorations for composite resins in posterior teeth between 24 and 31 years of age. This variable was obtained from the clinical examination of restorations in two different OHSs, i.e., OHS-06 and OHS 2013. Restoration replacement was defined when an amalgam restoration assessed in 2006 was completely removed and replaced with a composite restoration in 2013.

\section{Tooth-level variables}

Tooth-level variables included: a. Number of restored dental surfaces at age 31 - one; or two or more; $b$. self-reported estimated time of restoration in mouth at 24 years old - up to 1 year, $1-5$ years, 6-10 years or more than 10 years; ${ }^{8}$ c. dental group molars or pre-molars. 


\section{Personal-level variables}

Personal-level variables used in this study were obtained from different assessments carried out in the context of the larger birth cohort study. Self-reported skin color at age 24 was dichotomized into whites and blacks (browns and blacks). Racial classification in Brazil relies primarily on skin color or physical appearance - rather than explicitly using race, Brazilians more often rely on the language of skin color. ${ }^{22}$ Educational level at 31 years of age was collected in years, and later categorized into three groups ( $\geq 12 ; 9$ to 11 and $\leq 8$ years). Family income at age 31 was a continuous variable (BRL), which was subsequently categorized into tertiles and then, dichotomized into higher ( $2^{\text {nd }}$ and $3^{\text {rd }}$ tertiles $)$ and lower ( $1^{\text {st }}$ tertile) tertiles.

Dental service payment mode at age 31 was collected as follows: public free; private health insurance; and out-of-pocket. The 1997 Decayed, Missing and Filled index (DMFT) at age 24 was used to assess dental caries experience, and was later categorized into tertiles. Self-perception of dental aesthetics was collected through the following question: "Considering the appearance of your teeth, are you...", followed by the options: a) very satisfied; b) satisfied; c) neither satisfied nor dissatisfied; d) unsatisfied e) very dissatisfied. Participants who responded "very satisfied," "satisfied," and "neither satisfied nor dissatisfied" were regrouped as "satisfied/indifferent"; while those who responded "unsatisfied" and "very dissatisfied" were treated as "unsatisfied".

Dental examinations were carried out by six dentists from the Graduate Program in Dentistry of the Federal University of Pelotas (UFPel). All examiners and interviewers were trained and calibrated according to standardized procedures. Diagnostic reproducibility was measured by Kappa statistics, and the lowest kappa value observed in this study was 0.65 . In addition, to quality control, $10 \%$ of all interviews were repeated with a short version of the questionnaire where no report errors were detected.

\section{Data analysis}

Stata statistical package, version 12.0, was used for statistical analysis. Descriptive analysis determined the absolute and relative frequency of restoration-related variables, as well as the occurrence of amalgam replacement during the study period. To analyze the factors associated with replacement of amalgam restorations, a multilevel Poisson regression model was used, ${ }^{23}$ considering mixed effects and two hierarchical levels: tooth- (level 1) and personal-level (level 2) variables. Independent variables were included in the multivariate model according to a theoretical model described in Figure 1. Socioeconomic and demographic factors were placed in the most distal group of variables, followed by dental service utilization, dental caries experience and self-perceived dental appearance. Tooth-level variables were taken as proximal variables. Variables were adjusted by co-variates from the same and from the higher levels of the model. Inside each variable level, a backward stepwise procedure was used to select variables that should be kept in the final model. Only variables with $p \leq 0.250$ were maintained in the final model. The interaction between skin color and family income was also investigated. Incidence rate ratios and their $95 \%$ confidence intervals were estimated. Goodness of fit of multilevel models was assessed using deviance (-2 loglikelihood). Median Incidence Rate Ratio (MIRR) was assessed to estimate the individual level variance of multilevel models. MIRR permits expression of cluster level variance in the IRR scale, and, considering the present study, can be conceptualize as the increased risk of replacement that (in median) a restoration from lower risk individual would have if moving to another individual with higher risk. ${ }^{24}$

\section{Results}

A total of 539 individuals were assessed in the OHS-13, which corresponds to a response rate of $59.9 \%$. Regarding amalgam restorations, 385 individuals (corresponding to 1,207 amalgam restorations) were assessed in OHS-06. Considering this sample size, a mean of 3 restorations per subject, an alpha of 0.05 , an ICC of 0.47 , a 1:1 ratio of exposed/unexposed groups and an outcome incidence of $19 \%$, this study has $80 \%$ power to detect incidence rate ratios of 1.42 or greater. Among this 


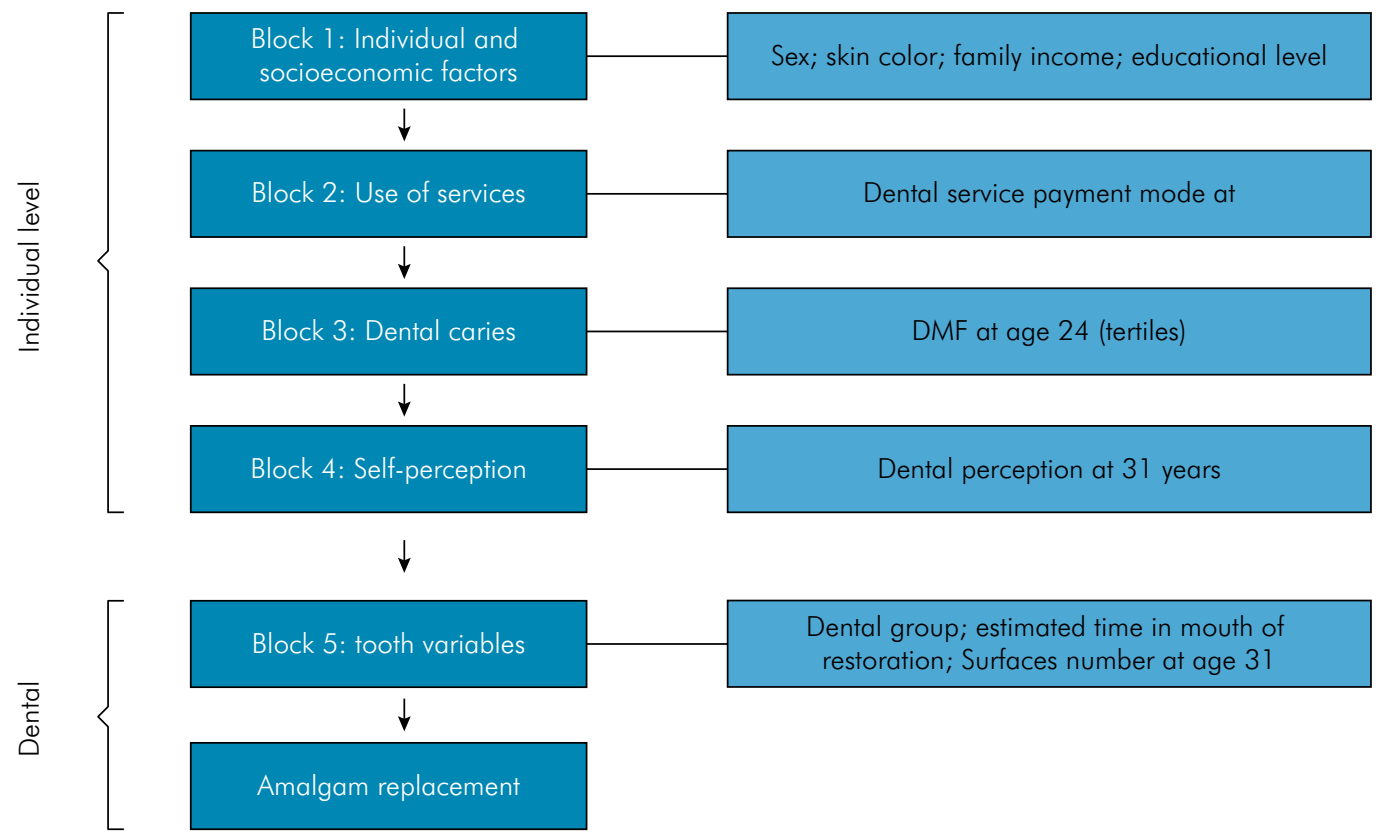

Figure 1. Theoretical model for analysis of amalgam replacement.

sample, 246 individuals presented 718 amalgam restorations in 2006, and these were effectively analyzed in this study (Figure 2). Considering all amalgam posterior restorations observed at 24 years of age, $642(89.4 \%)$ were located in molars and $76(10.6 \%)$ in premolars. At 24 years of age, $38 \%$ of restorations were estimated to be in mouth from six to ten years and $31 \%$ for more than ten years. Most of these restorations $(69.6 \%)$ had only one surface. From the total number of amalgam restorations presented at age 24, 136 (18.9\%) were replaced by composite resins in the seven subsequent years. Table 1 presents the distribution of 385 individuals with amalgam restorations assessed in OHS-06 and the 246 individuals assessed in OHS-13, which were included in this study according to individual-and tooth-level variables. Most of individuals included in this study were woman (53.25\%), whites (84.2\%) and individuals with schooling greater or equal to 12 years (53.5\%). Moreover, the distribution of initial sample was similar to the individuals included in the study (Table 1).

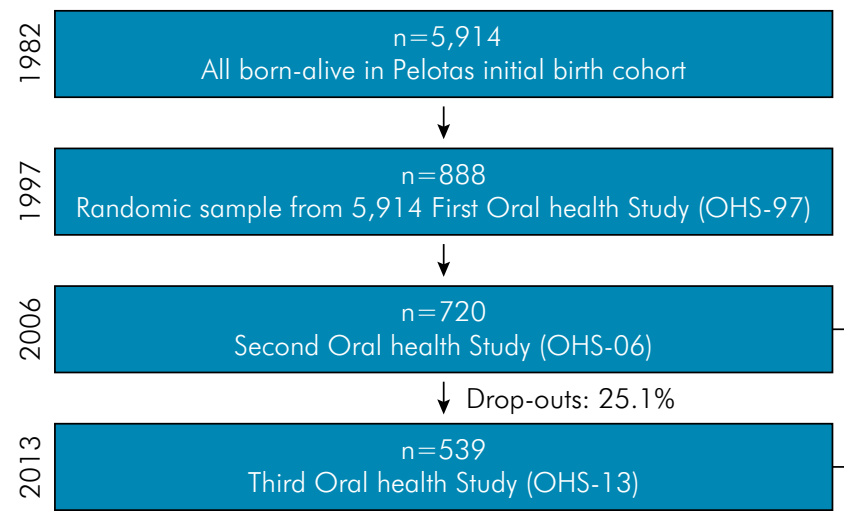

385 individuals with 1,207 amalgam restorations

$\downarrow$ Drop-outs: $36.1 \%$

246 individuals with 718 amalgam restorations From 718 amalgam restorations, 136 (18.9\%) were replaced by composite

Figure 2. Flow diagram of cohort follow-ups 
Table 1. Amalgam restorations in posterior teeth by socio-economic, oral health, and dental service utilization variables in a sample of young adults. Pelotas, RS, Brazil. $(n=246)$.

\begin{tabular}{|c|c|c|}
\hline \multirow{2}{*}{ Variable/Category } & Final sample (31 years) & Initial sample (24 years) \\
\hline & $\mathrm{n}(\%)$ & $\mathrm{n}(\%)$ \\
\hline \multicolumn{3}{|l|}{ Level 2 - Individual-level variables } \\
\hline \multicolumn{3}{|l|}{ Block 1} \\
\hline Sex & 246 & 385 \\
\hline Male & $115(46.75)$ & $192(49.87)$ \\
\hline Female & $131(53.25)$ & $193(50.13)$ \\
\hline Skin color & 240 & 379 \\
\hline White & $202(84.17)$ & $319(84.17)$ \\
\hline Black & $38(15.83)$ & $60(15.83)$ \\
\hline Family income at 31 yrs. (tertiles) & 216 & - \\
\hline Lowest tertile $\left(1^{\text {st }}\right)$ & $72(33.33)$ & \\
\hline Highest tertiles ( $2^{\text {nd }}$ and $\left.3^{\text {rd }}\right)$ & $144(66.67)$ & \\
\hline Educational level at age 31 (years) & 226 & - \\
\hline$\leq 8$ & $34(15.04)$ & \\
\hline 9 to 11 & $71(31.42)$ & \\
\hline$\geq 12$ & $121(53.54)$ & \\
\hline \multicolumn{3}{|l|}{ Block 2} \\
\hline Dental service payment mode at age 31 & 244 & - \\
\hline Out-of-pocket & $139(56.97)$ & \\
\hline Public free & $51(20.90)$ & \\
\hline Private health insurance & $54(22.13)$ & \\
\hline \multicolumn{3}{|l|}{ Block 3} \\
\hline DMFT at age 24 (tertiles) & 246 & 385 \\
\hline First & 45 (18.29) & $96(24.94)$ \\
\hline Second & $111(45.12)$ & $152(39.48)$ \\
\hline Third & $90(36.59)$ & $137(35.58)$ \\
\hline \multicolumn{3}{|l|}{ Block 4} \\
\hline Satisfaction with dental appearance & 246 & - \\
\hline Satisfied / indifferent & $176(71.54)$ & \\
\hline Unsatisfied & $70(28.46)$ & \\
\hline \multicolumn{3}{|l|}{ Level 1 - Tooth-level variables } \\
\hline \multicolumn{3}{|l|}{ Block 5} \\
\hline Number of restored surfaces at age 31 & 718 & - \\
\hline One & $500(69.64)$ & \\
\hline Two or more & $218(30.36)$ & \\
\hline Restoration estimated time in mouth at age 24 (years) & 671 & 1,145 \\
\hline$\leq 1$ & $55(8.20)$ & $97(8.47)$ \\
\hline 1 to 5 & $148(22.06)$ & $242(21.14)$ \\
\hline 6 to 10 & $258(38.45)$ & $479(41.83)$ \\
\hline$\geq 10$ & $210(31.30)$ & $327(28.56)$ \\
\hline Dental group & 718 & 1,207 \\
\hline Molars & $642(89.42)$ & $1,074(88.98)$ \\
\hline Pre-molars & $76(10.58)$ & $133(11.02)$ \\
\hline Amalgam restorations & 718 & - \\
\hline Replaced & $136(18.94)$ & \\
\hline Not replaced & $582(81.06)$ & \\
\hline
\end{tabular}


Results of multilevel Poisson regression are displayed in Table 2. After adjustments, blacks presented a lower risk for replacement of amalgam for composite resin restorations, compared with white individuals (IRR - 0.39 [95\% CI 0.16-0.95]). Individuals with high educational levels at age 31 were more likely to have their posterior amalgam restorations replaced with composite resins. In addition, individuals who had used private dental services showed a lower risk of having their posterior amalgam restorations replaced, compared to individuals who had used private dental services (out-of-pocket) $(p=0.036)$.

Considering tooth-level variables, the number of surfaces was directly associated with replacement of restorations. Amalgam restorations with two or more surfaces at age 24 showed an IRR 2.80 times greater for replacement, compared to those with only one surface. On the other hand, no differences were observed between molars and premolars $(p=0.152)$, as well as among different categories of restoration estimated time in mouth $(p=0.929)$.

There was a significant interaction between skin color and family income at age 31 . Black individuals from the poorer tertile presented a lower risk of replacement of amalgam restorations, compared with white individuals from the higher income tertiles. In addition, whites from the lower tertile and non-whites from the higher income tertiles presented similar risks, when compared to the reference group (whites, higher income tertile). Model-predicted replacement frequencies for categories originated from interactions between skin color and income from the final model, adjusted for all co-variables from both individual and tooth level are displayed in Figure 3. The predicted frequency of replacement in white individuals from higher income tertiles was $19.4 \%$, while in black individuals from the lowest income tertile individuals was $3.7 \%$.

The MIRR of full adjusted model was 1.31 i.e., there is an increase on risk of replacement of $31 \%$ if a restoration from the lowest risk individual was moved to the highest risk individual.

\section{Discussion}

The present oral health study, nested in a birth cohort investigation, was the first to show that replacement of amalgam restorations can be as high after seven years of follow up. It is important to note that although restorations have been assessed only at ages 24 and 31, the replacement of amalgam for composite resin is evident due to both dental materials being visually distinct from each other. On the other hand, replacement of an amalgam restoration with a new filling made of the same dental material could not be assessed in this study. Our investigation also revealed a strong influence of individual factors - such as skin color, educational level and dental services payment mode - on amalgam replacement. Further, the study showed that the increase on the number of restored surfaces was associated with an increase in the risk of amalgam replacement.

The association between oral health outcomes such as caries and periodontal disease with skin color is well reported in the literature, with blacks consistently showing poorer oral health conditions ${ }^{25-30}$. However, studies on replacement of restorations have focused only on specific dental materials and clinical outcomes. ${ }^{31,32}$ Dentists spend about $50 \%$ of their time repairing or replacing restorations and little is known about individual and contextual factors and their relationship with replacement of restorations. ${ }^{33}$ A recent study carried by our group in four different cities in Brazil, including Pelotas, observed that black patient had less risk of receiving replacement of ill-adapted amalgam restoration with composite resin and finishing and polishing when compared with the white patient even as black patients receive referrals for cheaper treatments. ${ }^{34}$ In this way, it was investigated the influence of the skin color on the decision to extract or retain a decayed tooth. ${ }^{35}$ The results showed significative influence of skin color on dentist's decision make treatment with worse results associated with black skin color. In the United States and Latin America, including Brazil, skin color is strongly linked not only to individual socio-economic disadvantage,$^{36,37}$ but also to various dimensions of area deprivation. Blacks are more likely to live in poor, segregated areas, which, more often than not, lack access to the most up-to-date and high quality (oral) health services. Taken together, these individual- and area-based factors may decrease the likelihood of replacement of amalgam restorations among blacks. ${ }^{38}$ 
Table 2. Crude (c) and adjusted (a) risk ratio (RR) for replacement of amalgam restorations with composite resins in a sample of young adults, according to individual- and tooth-level variables. Pelotas, RS, Brazil. Multilevel analysis ( $\mathrm{n}=246$ individuals; 718 restorations).

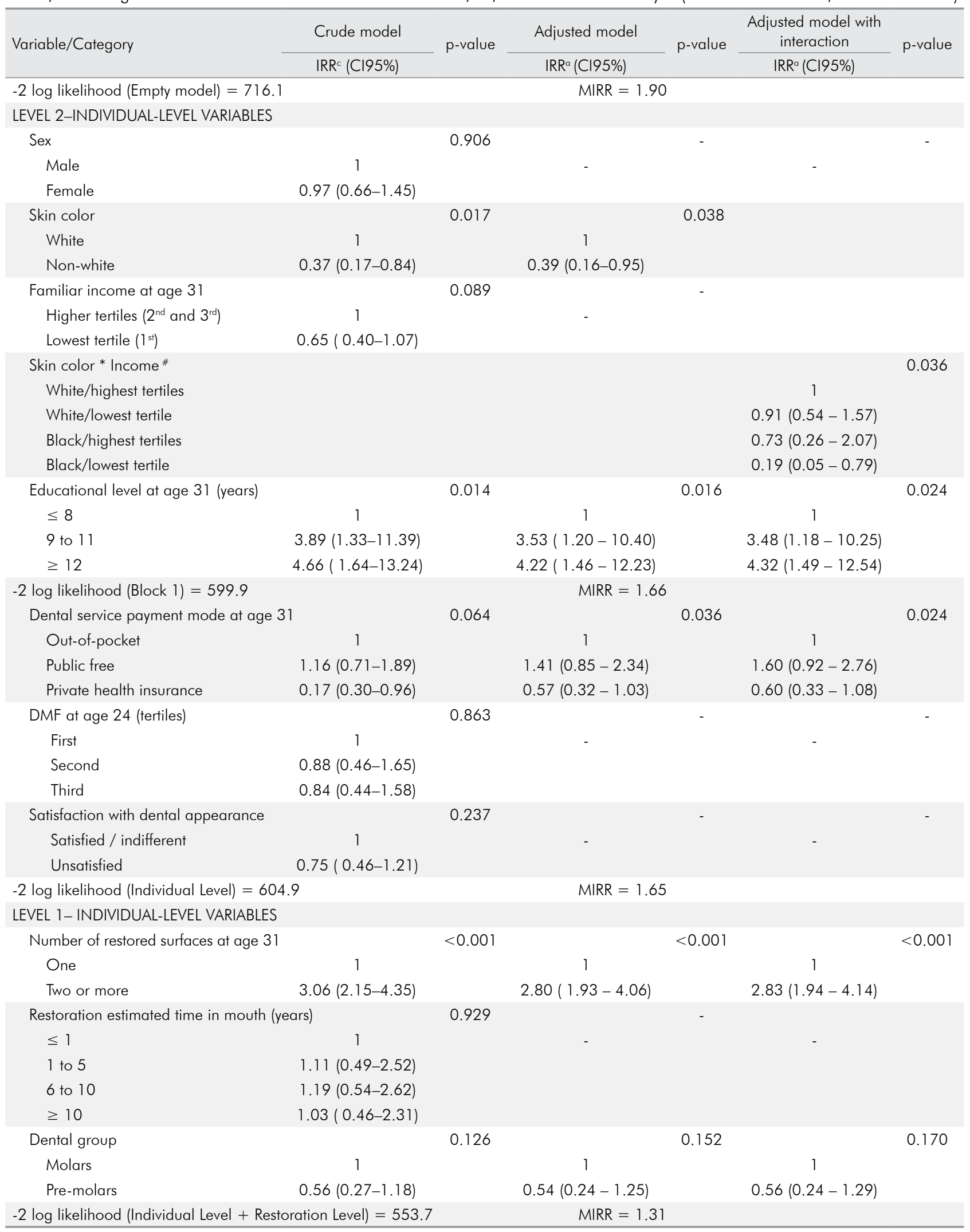

MIRR: Median Incidence Rate Ratio; \# Interaction between skin color and income was adjusted for all variables included in the final model. 


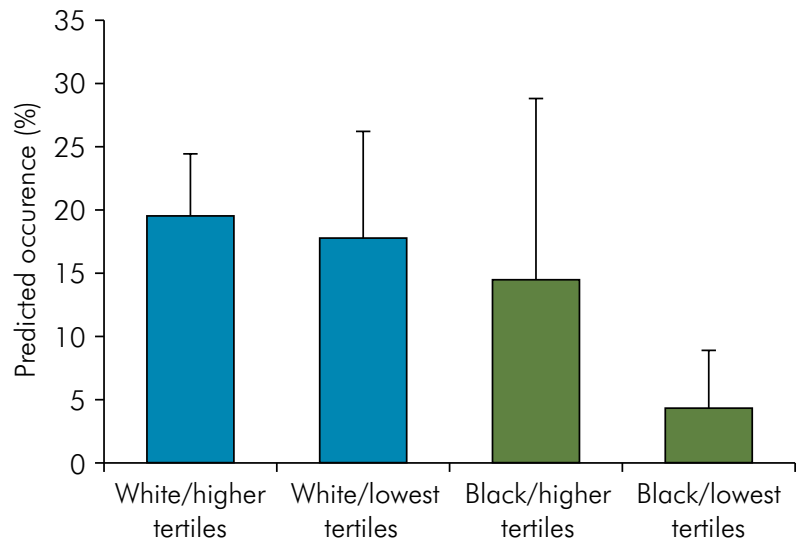

Figure 3. Predicted occurrence of amalgam replacement (\% (Cl 95\%)) for composite resin by individuals' skin color and familiar income. Results adjusted by final model.

Our findings also reveal an unexpected interplay between skin color and income, which extends beyond their main additive effects, and includes a strong interaction between these two factors: black respondents from a low socio-economic background were less likely to have their posterior amalgam restorations replaced with composite resins. As long as replacement of amalgam restorations with composite resins is a valued procedure in current dental practice, ${ }^{18,19}$ blacks from low-income tertiles are the least likely to be subjected to such a procedure. It should be noted, though, that replacement of amalgam restorations does not come without risks, and may not represent the best clinical decision depending on a number of factors, particularly when it comes to restoring posterior teeth. ${ }^{39,40}$ In some way, this leads poor blacks to being less exposed to a valued clinical procedure (use of composite resins), while also retaining their amalgam, but still reliable, posterior restorations.

Our findings showed that educational level affected the replacement of amalgam restorations, increasing the risk of replacement more than fourfold among people with high educational level, compared with those with fewer years of formal education. The literature has shown that the increase of educational level is closely associated with the search for treatments to improve dental esthetics. ${ }^{17,41}$ Patients with high socioeconomic status, presenting amalgam restorations, can be more likely to demand replacement of these restorations for esthetic purposes. This may lead to replacement of restoration without clinical indication. ${ }^{18,19}$ The lack of association of caries experience with replacement of amalgam may contributes to this explanation. It is well known that dental caries are strongly associated with lower socioeconomic status and a study conducted in this same cohort showed that individuals with high caries experience presented more restoration failures. ${ }^{8}$ However, an important limitation is the lack of information on the motivation for restoration replacement; we cannot rule out the hypothesis that some restorations were replaced due to partial or complete absence of amalgam. In fact, it is impossible to define the true reasons for replacement, although our results indicate that reasons unrelated to restoration failures were more likely to take place. Moreover, we should consider that the rate of restoration failure reported in some studies was similar to the one observed in the present study, reaching $20 \%$ in ten years of follow-up, ${ }^{9,42}$ with an annual failure rate of $4 \% .{ }^{42}$

Dental service payment mode assessed at 31 years was associated with replacement of amalgam restorations. Individuals who had private health insurance presented a lower risk of replacement compared with those who accessed out-of-pocket dental services. Health insurance plans usually do not cover procedures without unequivocal biological need, as is the case of restoration replacements that take place merely for aesthetic reasons. Health insurance companies work according to a profit-oriented perspective and thus do not replace restorations only for aesthetic reasons. On the other hand, public free service showed similar risk to out-of-pocket services and was not associated with replacement of amalgam posterior restorations. This lack of association was unexpected. However, different from insurance companies, there is a lack of effective standardization of indications/procedures performed in dental public health services in Brazil. ${ }^{43,44}$ Considering that most of dentists from private clinics also work in public dental services we may hypothesize that they apply the same criteria in both settings, probably wasting public resources.

Among tooth-level variables, our results showed that the greater the number of surfaces involved in amalgam restorations, the higher the risk of 
replacement for composites. Large restorations are more evident and visible in the mouth and may compromise dental aesthetics more evidently; larger restorations are also more susceptible to failures.,45 It could be expected that replacements in premolars would be higher than in molars due to aesthetic reasons and because this tooth group presents a higher risk for failures when compared to molars. ${ }^{46}$ However, no differences were found between the two tooth groups. In fact, the lack of information about the reason of restoration replacement reported by individuals should be considered in results interpretations, which can introduce important bias in the study. The small number of amalgam restorations presented in premolars in 2006 may explain this lack of association in our study. Furthermore, it is a relatively small sample, which could difficult the identification of some differences. In addition, less invasive procedures, as finishing and polishing or repairs on the restorations cannot be detected by methods used and, consequently, were not included in our analysis. In this way, small amalgam restorations fractured in only one surface and repaired with composite were not detectable in our examinations and, consequently, not computed in analysis. Besides, it is important highlight that the generalizability of present results can be limited to population with the similar socioeconomic characteristics in Brazil. Similarly, we have not observed a significative relationship among different categories of restoration estimated time in mouth. This can be explained in two ways, since with the passage of time older restorations tend to fail more, the no association of replacement of amalgam restorations has been motived to aesthetic reasons and not due to failures. The other possible explanation is linked to data collection of this variable. The time estimate in moth of restoration was self-reported, this can lead to a poor accurate data, especially when the patients have several restorations placed in the same quadrant at different time points. The self-reported nature of these data is a limitation to consider.

\section{Conclusion}

Substitution of amalgam restorations for composite resins in posterior teeth was a common procedure and our results demonstrate that skin color affect the replacement of amalgam for composite resin in posterior restorations. Both individual- and toothlevel factors play a key role in amalgam replacement in posterior teeth.

\section{References}

1. Kassebaum NJ, Bernabé E, Dahiya M, Bhandari B, Murray CJ, Marcenes W. Global burden of untreated caries: a systematic review and metaregression. J Dent Res. 2015 May;94(5):650-8. https://doi.org/10.1177/0022034515573272

2. Demarco FF, Correa MB, Cenci MS, Moraes RR, Opdam NJ. Longevity of posterior composite restorations: not only a matter of materials. Dent Mater. 2012;28(1):87-101. https://doi.org/10.1016/i.dental.2011.09.003

3. Chisini LA, Collares K, Cademartori MG, Oliveira LJC, Conde MCM, Demarco FF, et al. Restorations in primary teeth: a systematic review on survival and reasons for failures. Int J Paediatr Dent.. 2018;28(2):123-39. https://doi.org/10.1111/ipd.12346

4. Dutra ER, Chisini LA, Cademartori MG, Oliveira LJ, Demarco FF, Correa MB. Accuracy of partial protocol to assess prevalence and factors associated with dental caries in schoolchildren between 8-12 years of age. Cad Saude Publica. 2018;34(4):e00077217. https://doi.org/10.1590/0102-311x00077217

5. Alexander G, Hopcraft MS, Tyas MJ, Wong R. Dentists' restorative decision-making and implications for an 'amalgamless' profession. Part 3: dentists' attitudes. Aust Dent J. 2016 Dec;61(4):502-13. https://doi.org/10.1111/adj.12419

6. Tobi $\mathrm{H}$, Kreulen $\mathrm{CM}$, Vondeling $\mathrm{H}$, Amerongen WE. Cost-effectiveness of composite resins and amalgam in the replacement of amalgam Class II restorations. Community Dent Oral Epidemiol. 1999 Apr;27(2):137-43. https://doi.org/10.1111/j.1600-0528.1999.tb02003.x

7. Roeters FJ, Opdam NJ, Loomans BA. The amalgam-free dental school. J Dent. 2004 Jul;32(5):371-7. https://doi.org/10.1016/i.jdent.2004.02.008

8. Correa MB, Peres MA, Peres KG, Horta BL, Barros AD, Demarco FF. Amalgam or composite resin? Factors influencing the choice of restorative material. J Dent. 2012 Sep;40(9):703-10. https://doi.org/10.1016/i.jdent.2012.04.020

9. Opdam NJ, Bronkhorst EM, Roeters JM, Loomans BA. A retrospective clinical study on longevity of posterior composite and amalgam restorations. Dent Mater. 2007;23(1):2-8. https://doi.org/10.1016/i.dental.2005.11.036 
- Skin color affect the replacement of amalgam for composite in posterior restorations: a birth-cohort study

10. Rodolpho PAR, Donassollo TA, Cenci MS, Loguercio AD, Moraes RR, Bronkhorst EM, et al. 22-Year clinical evaluation of the performance of two posterior composites with different filler characteristics. Dent Mater. 2011;27(10):955-63.

11. Bernardo M, Luis H, Martin MD, Leroux BG, Rue T, Leitão J, et al. Survival and reasons for failure of amalgam versus composite posterior restorations placed in a randomized clinical trial. J Am Dent Assoc. 2007 Jun;138(6):775-83. https://doi.org/10.14219/jada.archive.2007.0265

12. Sande FH, Opdam NJ, Rodolpho PA, Correa MB, Demarco FF, Cenci MS. Patient risk factors' influence on survival of posterior composites. J Dent Res. 2013 Jul;92(7 Suppl):78S-83S. https://doi.org/10.1177/0022034513484337

13. Sande FH, Collares K, Correa MB, Cenci MS, Demarco FF, Opdam N. Restoration survival: revisiting patients' risk factors through a systematic literature review. Oper Dent. 2016 Sep;41 S7:S7-26. https://doi.org/10.2341/15-120-LIT PMID:27689931

14. Gilmour AS, Evans P, Addy LD. Attitudes of general dental practitioners in the UK to the use of composite materials in posterior teeth. Br Dent J. 2007 May;202(12):E32. https://doi.org/10.1038/bdj.2007.472

15. Burke FJ, McHugh S, Hall AC, Randall RC, Widstrom E, Forss H. Amalgam and composite use in UK general dental practice in 2001. Br Dent J. 2003;194(11):613-8. https://doi.org/10.1038/sj.bdj.4810258

16. Rosenstiel SF, Land MF, Rashid RG. Dentists' molar restoration choices and longevity: a web-based survey. J Prosthet Dent. 2004 Apr;91(4):363-7. https://doi.org/10.1016/i.prosdent.2004.02.004

17. Silva FB, Chisini LA, Demarco FF, Horta BL, Correa MB. Desire for tooth bleaching and treatment performed in Brazilian adults: findings from a birth cohort. Braz Oral Res. 2018 Mar;32(0):e12. https://doi.org/10.1590/1807-3107bor-2018.vol32.0012

18. Lucarotti PS, Holder RL, Burke FJ. Outcome of direct restorations placed within the general dental services in England and Wales (Part 1): variation by type of restoration and re-intervention. J Dent. 2005 Nov;33(10):805-15. https://doi.org/10.1016/i.jdent.2005.03.008PMID:16221519

19. Vidnes-Kopperud S, Tveit AB, Gaarden T, Sandvik L, Espelid I. Factors influencing dentists' choice of amalgam and tooth-colored restorative materials for Class II preparations in younger patients. Acta Odontol Scand. 2009;67(2):74-9. https://doi.org/10.1080/00016350802577800

20. Elderton RJ. Restorations without conventional cavity preparations. Int Dent J. 1988 Jun;38(2):112-8.

21. Elm E, Altman DG, Egger M, Pocock SJ, Gøtzsche PC, Vandenbroucke JP. The Strengthening the Reporting of Observational Studies in Epidemiology (STROBE) statement: guidelines for reporting observational studies. Lancet. 2007 Oct;370(9596):1453-7. https://doi.org/10.1016/S0140-6736(07)61602-X

22. Santos RV, Fry PH, Monteiro S, Maio MC, Rodrigues JC, Bastos-Rodrigues L, et al. Color, race, and genomic ancestry in Brazil: dialogues between anthropology and genetics. Curr Anthropol. 2009 Dec;50(6):787-819. https://doi.org/10.1086/644532

23. Barros AJ, Hirakata VN. Alternatives for logistic regression in cross-sectional studies: an empirical comparison of models that directly estimate the prevalence ratio. BMC Med Res Methodol. 2003 Oct;3(1):21. https://doi.org/10.1186/1471-2288-3-21

24. Merlo J, Chaix B, Ohlsson H, Beckman A, Johnell K, Hierpe P, et al. A brief conceptual tutorial of multilevel analysis in social epidemiology: using measures of clustering in multilevel logistic regression to investigate contextual phenomena. J Epidemiol Community Health. 2006 Apr;60(4):290-7. https://doi.org/10.1136/jech.2004.029454

25. Peres MA, Peres KG, Barros AJ, Victora CG. The relation between family socioeconomic trajectories from childhood to adolescence and dental caries and associated oral behaviours. J Epidemiol Community Health. 2007 Feb;61(2):141-5. https://doi.org/10.1136/jech.2005.044818

26. Dalazen CE, De Carli AD, Bomfim RA, Santos ML. Contextual and individual factors influencing periodontal treatment needs by elderly brazilians: a multilevel analysis. PLoS One. 2016 Jun;11(6):e0156231. https://doi.org/10.1371/journal.pone.0156231

27. Vettore MV, Marques RA, Peres MA. [Social inequalities and periodontal disease: multilevel approach in SBBrasil 2010 survey]. Rev Saude Publica. 2013 Dec;47 Suppl 3:29-39. Portuguese. https://doi.org/10.1590/S0034-8910.2013047004422 PMID:24626579

28. Peres MA, Peres KG, Frias AC, Antunes JL. Contextual and individual assessment of dental pain period prevalence in adolescents: a multilevel approach. BMC Oral Health. 2010 Aug;10(1):20. https://doi.org/10.1186/1472-6831-10-20

29. Sabbah W, Tsakos G, Chandola T, Sheiham A, Watt RG. Social gradients in oral and general health. J Dent Res. 2007 Oct;86(10):992-6. https://doi.org/10.1177/154405910708601014

30. Chalub LL, Martins CC, Ferreira RC, Vargas AM. functional dentition in brazilian adults: an investigation of Social Determinants of Health (SDH) using a multilevel approach. PLoS One. 2016 Feb;11(2):e0148859. https://doi.org/10.1371/journal.pone.0148859

31. Sharif MO, Catleugh M, Merry A, Tickle M, Dunne SM, Brunton P, et al. Replacement versus repair of defective restorations in adults: resin composite. Cochrane Database Syst Rev. 2014 Feb;(2):CD005971. https://doi.org/10.1002/14651858.CD005971.pub3

32. Blum IR. Summary of: repair vs replacement of failed restorations in general dental practice: factors influencing treatment choices and outcomes. Br Dent J. 2015 Jan;218(1):22-3. https://doi.org/10.1038/sj.bdj.2014.1164

33. Miör IA, Shen C, Eliasson ST, Richter S. Placement and replacement of restorations in general dental practice in Iceland. Oper Dent. 2002 Mar-Apr;27(2):117-23.

34. Chisini LA, Noronha TG, Ramos EC, Santos-Junior RB, Sampaio KH, Faria-E-Silva AL, et al. Does the skin color of patients influence the treatment decision-making of dentists? A randomized questionnaire-based study. Clin Oral Investig. 2019 Mar;23(3):1023-30. https://doi.org/10.1007/s00784-018-2526-7

35. Cabral ED, Caldas AF Jr, Cabral HA. Influence of the patient's race on the dentist's decision to extract or retain a decayed tooth. Community Dent Oral Epidemiol. 2005 Dec;33(6):461-6. https://doi.org/10.1111/i.1600-0528.2005.00255.x 
36. Telles E, Flores RD, Urrea-Giraldo F. Pigmentocracies: educational inequality, skin color and census ethnoracial identification in eight Latin American countries. Res Soc Stratification Mobility. 2015;40:39-58. https://doi.org/10.1016/i.rssm.2015.02.002

37. Edelstein BL. Disparities in oral health and access to care: findings of national surveys. Ambul Pediatr. 2002 Mar-Apr;2(2 Suppl):141-7. https://doi.org/10.1367/1539-4409(2002)002<0141:DIOHAA>2.0.CO;2

38. Phelan JC, Link BG. Is racism a fundamental cause of inequalities in health? Annu Rev Sociol. 2015;41(1):311-30. https://doi.org/10.1146/annurev-soc-073014-112305

39. Moncada G, Fernández E, Mena K, Martin J, Vildósola P, Oliveira Junior OB, et al. Seal, replacement or monitoring amalgam restorations with occlusal marginal defects? Results of a 10-year clinical trial. J Dent. 2015 Nov; 43(11):1371-8. https://doi.org/10.1016/i.jdent.2015.07.012

40. Moncada G, Vildósola P, Fernández E, Estay J, Oliveira Júnior OB, de Andrade MF, et al. Longitudinal results of a 10-year clinical trial of repair of amalgam restorations. Oper Dent. 2015 Jan-Feb;40(1):34-43. https://doi.org/10.2341/14-045-C

41. Špali S, Katić V, Vidaković R, Šlaj M, Šlaj M. History of Orthodontic Treatment, Treatment Needs and Influencing Factors in Adolescents in Croatia. Cent Eur J Public Health. 2016 Jun;24(2):123-7. https://doi.org/10.21101/cejph.a4117

42. Casagrande L, Laske M, Bronkhorst EM, Huysmans MC, Opdam NJ. Repair may increase survival of direct posterior restorations - A practice based study. J Dent. 2017 Sep;64:30-6. https://doi.org/10.1016/i.ident.2017.06.002

43. Weber CM, Alves LS, Maltz M. Treatment decisions for deep carious lesions in the Public Health Service in Southern Brazil. J Public Health Dent. 2011;71(4):265-70. https://doi.org/10.1111/j.1752-7325.2011.00258.x

44. Chisini LA, Conde MC, Correa MB, Dantas RV, Silva AF, Pappen FG, et al. Vital pulp therapies in clinical practice: findings from a survey with dentist in Southern Brazil. Braz Dent J. 2015 Nov-Dec;26(6):566-71. https://doi.org/10.1590/0103-6440201300409PMID:26963197

45. Correa MB, Peres MA, Peres KG, Horta BL, Barros AJ, Demarco FF. Do socioeconomic determinants affect the quality of posterior dental restorations? A multilevel approach. J Dent. 2013 Nov;41(11):960-7. https://doi.org/10.1016/i.jdent.2013.02.010

46. Lubisich EB, Hilton TJ, Ferracane JL, Pashova HI, Burton B, Northwest P. Association between caries location and restorative material treatment provided. J Dent. 2011 Apr;39(4):302-8. https://doi.org/10.1016/i.jdent.2011.01.007 